\title{
COMO TRATAR AS IDENTIDADES NA PESQUISA LINGUÍSTICA
}

Letícia Rezende Stallone

\section{RESUMO}

Este artigo investiga questóes de identidades através da apresentação da tipologia desenvolvida por Vion $\left(1995^{1}, 1996^{2}\right)$. Procuramos demonstrar que, aliada a noções seminais em Sociolinguística Interacional, como enquadres (BATESON, 2002 ${ }^{3}$ ) e gêneros (KERBRATORECCHIONI \& TRAVERSO, 2004 $)$, a tipologia parece produtiva para entender as relaçóes próximas em sua complexidade e heterogeneidade.

PALAVRAS-CHAVE: identidades; tipos de discurso; relaçôes próximas

\section{Apresentação}

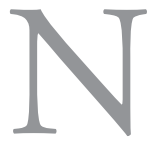

os primeiros dias de 2012, o Correio do Brasil traz uma reportagem a respeito das medidas adotadas pela China para conter a invasão cultural do Ocidente. Segundo a publicação, o governo do referido país acredita que a cultura chinesa, apesar de forte, precisa ser protegida da ainda mais poderosa influência ocidental.

1 VION, R. "La Gestion pluridimensionnelle du dialogue" Cahiers de Linguistique Française, 17: 179-203, France, 1995.

2 VION, R. "L'analyse des interactions verbales" Les carnets du CEDISCOR, 4: 19-32. Paris: Presses de la Sorbonne Nouvelle, 1996.

3 BATESON, G. "Uma teoria sobre brincadeira e fantasia” In: RIBEIRO, B. T. \& GARCEZ, P. M. (orgs.) Sociolinguistica interacional. São Paulo: Ediçôes Loyola, 2002, 85-105.

4 KERBRAT-ORECCHIONI, C. \& TRAVERSO, V. “Types d'interactions et genres de l'oral" Langages 1, n. 153: 41 - 51. France, 2004. 
Esta influência é denominada por Hu Jintao, atual líder político do país, como uma "força hostil internacional" que está intensificando "seus golpes estratégicos" para ocidentalizar a China e separar o país. Para Jintao, trata-se de uma infiltração de foco ideológico e cultural, que exige uma reação da China, uma reforma para poupar suas tradiçóes.

A reforma cultural, elaborada pelo Partido Comunista da China (PCC), prevê a revitalização da indústria cultural do país, através do controle da entrada de manifestaçóes culturais ocidentais como, por exemplo, o fim de programas de entretenimento estrangeiros veiculados pela televisão chinesa em canais fechados.

Apesar da reforma remeter a fantasmas da Revolução Cultural de Mao-Tsé-Tung, são as questôes identitárias que nos chamam mais a atenção. Como será possível controlar o contato entre os povos, restringindo acesso aos outros quando este é tâo disponível e disseminado? $\mathrm{Na}$ era da internet, das imigrações, da compressão espaço-tempo, que ocasiona um aumento na velocidade de discursos e imagens disponibilizados em tempo real, os povos se aproximam, tornando cada vez mais difícil de serem delimitados e categorizados em naçóes como os chineses, os americanos, etc.

O próprio conceito de identidade nacional começa a parecer instável, uma vez que vem se confundindo com etnicismo e raça, à medida que estabelecemos links globais que transcendem e até subvertem as fronteiras nacionais (PITTAM, 1999, p. $114^{6}$ ).

A tarefa do governo chinês não é das mais fáceis. Segundo Fabrício ${ }^{7}$ (2006), nos dias de hoje, não há como adotar um ponto de vista simplista a respeito de fenômenos sociais, "está em operação um campo de forças plurais que entrelaça uma série de novos significados, modos de produção de sentido, práticas, técnicas, instituições" (FABRÍCIO, 2006, p. 4).

5 "China adota medidas para conter 'invasão cultural' do ocidente" Correio do Brasil, http://correiodobrasil.com.br/bbc-brasil/china-adota-medidas-para-conter-\%E2\%80\%98invasao-cultural\%E2\%80\%99-do-ocidente/351227/, 04/01/2012.

6 PITTAM, J. “The Historical and Emergent Enactment of Identity in Language” Research on Language and Social Interaction: vol. 32: 111-117, Iowa: Lawrence Erlbaum Associates, 1999.

7 FABRÍCIO, B. F. "Introdução: uma linguística aplicada mestiça e ideológica: interrogando o campo como linguista aplicado" In: MOITA-LOPES (org.) Por uma linguística aplicada indisciplinar. São Paulo: Parábola Editorial, 2006, p. 13-42. 
A autora refere-se ao momento atual como uma "trama movente", um "trânsito permanente", refratário a verdades calcificadas, compreendendo que é cada vez mais difícil traçar limites sólidos entre aquilo que é norma e o que é desvio, por exemplo.

Segundo a autora, este é um dos motivos para vermos mais trabalhos de pesquisa sobre as "franjas do sistema globalizado", as periferias. Trata-se de uma mudança de rumo das pesquisas que não buscam a salvação dos destituídos, mas que veem nesses espaços novas formas de percepção "não comprometid[as] com lógicas e sentidos históricos viciados" (FABRÍCIO, 2006, p. 52) ${ }^{8}$.

A saliência destas minorias demonstra, ainda segundo a autora, implicações para a construção do presente e de futuros sociais possíveis, "menos aprisionadores e mais comprometidos com a transformação de situaçóes de exclusão social em diversas áreas, causadoras de sofrimento humano" (FABRÍCIO, 2006, p. 52)

É esta tendência em LA (linguística aplicada) que nos autoriza, por exemplo, a considerar a investigação das relações próximas como fundamental no âmbito da pesquisa nacional. Tentar compreender estas relaçóes, transformando-as em objeto de pesquisa, ajuda-nos a torná-las mais acessíveis aos próprios sujeitos que as constroem. Acreditamos que disponibilizar uma radiografia destas relaçóes, que são essencialmente não institucionalizadas, é uma forma de dar mais poder aos indivíduos para conhecerem melhor a forma como se engajam em atividades no dia a dia, como estabelecem comunicação com o restante do mundo.

Este artigo é um recorte de uma pesquisa de doutorado mais ampla que se debruça sobre essas relaçóes de intimidade. Questionando, neste contexto, os antigos direcionamentos de pesquisa no âmbito nacional, propomos a disseminação deste tipo de pesquisa, colocando-o cada vez mais acessível ao senso comum.

8 FABRÍCIO, B. F. "Introdução: uma linguística aplicada mestiça e ideológica: interrogando o campo como linguista aplicado” In: MOITA-LOPES (org.) Por uma linguistica aplicada indisciplinar. São Paulo: Parábola Editorial, 2006, p. 13-42.

9 FABRÍCIO, B. F. "Introdução: uma linguística aplicada mestiça e ideológica: interrogando o campo como linguista aplicado” In: MOITA-LOPES (org.) Por uma linguística aplicada indisciplinar. São Paulo: Parábola Editorial, 2006, p. 13-42. 
A preservação de valores tradicionais em detrimento da comunicação espontânea sem fronteiras, ou com fronteiras mais frouxas, e do fluxo contínuo de informaçóes nos remete, em contexto nacional, à medida proposta pelo deputado Aldo Rebelo para conter o estrangeirismo no Brasil. A medida, muito polemizada pela comunidade linguística, revela uma necessidade de fixar fronteiras e delimitar nações. Assim como a restrição da entrada de entretenimento estrangeiro em terras chinesas, esta medida mostra-se contrária ao movimento natural que vemos com o fenômeno da globalizaçáo.

Neste contexto, entre os teóricos da linguística, vemos por um lado os "subjetivistas", definidos por Cuche ${ }^{10}$ (2002) como aqueles que veem a identidade etnocultural como "nada além de um sentimento de vinculação ou uma identificação a uma coletividade imaginária em maior ou menor grau" (CUCHE, 2002, p. 181). E por outro lado, os teóricos "objetivistas" que postulam a concepção da identidade cultural como uma identidade que se define e se descreve, conforme Cuche,

a partir de um certo número de critérios determinantes, considerados como 'objetivos', como a origem comum (a hereditariedade, a genealogia) (...), o vínculo com o território, etc. Para os objetivistas um grupo sem língua própria, sem cultura própria, sem território próprio (...) não pode reivindicar uma identidade cultural autêntica. (CUCHE, 2002, p. 180).

Propomos traçar um caminho alternativo para tratar das identidades nesta pesquisa. Não seremos subjetivistas extremos, a ponto de reduzir a identidade a uma questão de escolha individual arbitrária em que "cada um seria livre para escolher suas identificações” (CUCHE, 2002, p. 181), mas tampouco postulamos a existência de categorias previamente determinadas e objetivas.

Segundo Pittam ${ }^{11}$ (1999), a apresentação do selfe a construção de identidades devem ser vistas no contexto de cada interação, e apesar de incluir um

10 CUCHE, D. A noção de cultura nas ciências sociais. Bauru: EDUSC, 2002.

11 PITTAM, J. "The Historical and Emergent Enactment of Identity in Language" Research on Language and Social Interaction: vol. 32: 111-117, Iowa: Lawrence Erlbaum Associates, 1999. 
contexto histórico, a natureza dinâmica, emergente e negociada é também responsável por determinar a forma como os indivíduos se posicionam em relação uns aos outros e às suas identidades.

Defendemos, assim, a necessidade de uma análise situacional, uma vez que entendemos que a identidade é co-construída no discurso, mas acreditamos como Pittam (1999) que estas duas propostas podem se complementar, levando em conta tanto o aspecto histórico quanto o aspecto situacional da construção de identidades.

As relaçóes próximas, por exemplo, não podem ser caracterizadas unicamente como relaçóes situadas, que nascem apenas da construção do discurso no momento de interação, é imprescindível considerar que se trata de relaçôes que vêm sendo construídas ao longo dos anos.

Assim, acreditamos ser necessário tratar primeiramente da forma como são definidas as atividades em que se engajam os participantes nas trocas interacionais e entender como se posicionam e se comportam, constituindo esta ou aquela atividade, desempenhando este ou aquele papel.

\section{Os gêneros, os tipos de discurso e os enquadres}

Ao tratar da noção de gênero em interaçóes orais, Kerbrat-Orecchioni e Traverso $^{12}$ (2004) afirmam que existem dois tipos de gêneros: um que denominam G1, referindo-se a categorias de textos mais ou menos institucionais numa determinada sociedade, os eventos de comunicação ${ }^{13}$; e outro que denominam G2, aqueles mais abstratos, "tipos de discurso caracterizados por certos traços de natureza retórico-pragmática” (KERBRAT-ORECCHIONI \& TRAVERSO, 2004, p. 42).

Segundo as autoras, um mesmo gênero (G1) pode ser, e na maioria das vezes é, constituído por vários tipos de discurso diferentes (G2). O que se mostra mais relevante são os tipos de discurso (G2), pois se localizam no nível da sequência e não no texto global; "são protótipos sequenciais que se encontram na base de toda composição textual, sendo os principais tipos:

12 KERBRAT-ORECCHIONI, C. \& TRAVERSO, V. Types d'interactions et genres de l'oral Langages 1/2004 (n.153), p. 41-51.

13 Événements de communication (KERBRAT-ORECCHIONI, C. \& TRAVERSO, V. Types d'interactions et genres de l'oral Langages 1/2004 (n.153), p. 41-51. 
a narrativa, a descrição, a argumentação" (KERBRAT-ORECCHIONI \& TRAVERSO, 2004, p. 42) ${ }^{14}$.

As autoras tratam da impureza dos gêneros orais, acreditando que a maior parte dos textos é composta por uma mistura de diversos tipos de sequências "portanto, diversos tipos de tipos" (KERBRAT-ORECCHIONI \& TRAVERSO, 2004, p. 44) ${ }^{15}$.

O G1 pode ser compreendido, sintagmaticamente, como uma sucessão ou uma imbricação de sequências relevantes de diferentes G2, ou seja, um evento comunicativo composto por diferentes tipos de discurso. No nosso caso, um evento comunicativo como um encontro entre amigos abarca uma quantidade grande de tipos de discurso: narrativos, argumentativos, avaliativos, por exemplo.

Enquanto os eventos comunicativos (G1) são baseados em critérios externos, ou seja, situacionais, como o local da interação, a natureza do formato participativo e o objetivo da interação, os tipos de discurso são determinados por critérios internos. De acordo com as autoras, uma argumentaçáo ou uma narrativa pode ser identificável como tal independentemente dos acontecimentos nos quais se inscreve. Esta identificaçâo se dá a partir de diferentes elementos do material linguístico e da organização discursiva como o emprego do tempo dos verbos e a sua forma sequencial, é devido ainda a características próprias do discurso oral como a intensidade da voz, o tamanho dos turnos de fala, as sobreposiçôes etc. (KERBRAT-ORECCHIONI \& TRAVERSO, 2004) ${ }^{16}$.

Esta distinção entre critérios externos e internos é antes elaborada por Vion, ${ }^{17}$ (1995) ao considerar que, numa dada interação, há um tipo de relaçâo dominante, que define o enquadre interacional, e os modos de posicionamento, aqueles que se encontram momentaneamente atualizados pela

14 KERBRAT-ORECCHIONI, C. \& TRAVERSO, V. Types d'interactions et genres de l'oral Langages $1 / 2004$ (n.153), p. 41-51.

15 KERBRAT-ORECCHIONI, C. \& TRAVERSO, V. Types d'interactions et genres de l'oral Langages 1/2004 (n.153), p. 41-51.

16 KERBRAT-ORECCHIONI, C. \& TRAVERSO, V. Types d'interactions et genres de l'oral Langages 1/2004 (n.153), p. 41-51.

17 VION, R. La Gestion pluridimensionnelle du dialogue. In : Cahiers de Linguistique Française 17: 179-203, 1995. 
ação dos sujeitos (VION, 1996) ${ }^{18}$. O autor propóe analisar a complexidade e a heterogeneidade das interaçôes, amparado em três princípios básicos: um princípio dialógico, um princípio de recursividade e um princípio de caráter hologramático ${ }^{19}$.

O princípio dialógico, que busca romper definitivamente com a dicotomia entre macro e micro, garante que um objeto provém, ao mesmo tempo, de uma ordem de determinação e seu contrário. Baseado na dialética de Hegel, este princípio sustenta que uma proposição (tese) não pode se pôr sem se opor a outra (antítese), em que a primeira é negada, transformada em outra que não ela mesma ("alienada”). Assim, uma dada interação pode ser, ao mesmo tempo, simétrica e complementar, cooperativa e competitiva.

O princípio de recursividade, amparado na logique hétérarchique proposta por Roulet $(1991)^{20}$, garante que os fenômenos não são mais determinados de maneira unidimensional, mas de forma recíproca. Nas palavras de Vion:

(...) ao mesmo tempo que são produtos de um sistema, os sujeitos transformam este sistema; eles obedecem a regras e normas que, ao serem postas em funcionamento, são por eles modificadas. Ao mesmo tempo que é determinada pela situação, a linguagem também a determina, em razão de sua dimensão ilocutória. ${ }^{21 ”}$ (VION, 1995, p. 180 [tradução minha\}] $)^{22}$.

18 VION, R. L'analyse des interactions verbales. In : La construction interactive des discours de la classe de langue. Les carnets du CEDISCOR, nr. 4, p. 19-32. Paris : Presses de la Sorbonne Nouvelle, 1996.

19 Hologrammatique. (VION, R. La Gestion pluridimensionnelle du dialogue. In : Cahiers de Linguistique Française 17: 179-203, 1995).

20 ROULET, E. "Vers une approche modulaire de l'analyse de l'interaction verbale" In: VÉRONIQUE, D. \& VION, R. (éds)Modéles de l'interaction verbale, 113-125, 1991.

21 (...) les sujets sont les produits d'un système en même temps qu'ils transforment ce système ; ils obéissent à des règles et des normes en même temps qu'en les faisant fonctionner ils les modifient. Le langage est déterminé par la situation en même temps que, par sa dimension illocutoire, il la détermine (VION, 1995, p. 180). VION, R. La Gestion pluridimensionnelle du dialogue. In : Cahiers de Linguistique Française 17: 179-203, 1995.

22 VION, R. La Gestion pluridimensionnelle du dialogue. In : Cahiers de Linguistique Française 17: 179-203, 1995. 
O princípio de caráter hologramático evidencia que a parte está no todo e o todo está nas partes. Ou seja, na relação entre sujeito e sociedade, pode-se dizer que o sujeito é uma parte da sociedade, ao mesmo tempo em que a sociedade está presente em cada sujeito, através da sua língua, sua cultura e etc.

A proposta de Vion $(1995,1996)$ nos parece produtiva para compreender o "espaço interacional" na complexidade das relaçóes, uma vez que, como o autor mesmo diz: "a linguística abandona a lógica da separação dos observáveis e passa a pensar a realidade dentro de sua complexidade e sua heterogeneidade" (VION, 1996, p. 31) 23.

Este posicionamento teórico nos remete ainda a outro autor, que trata da noção de hibridismo de gênero, vozes e discursos. Apesar de não dialogarem efetivamente, Sarangi $(2010)^{24}$ e Vion $(1995,1996)$ parecem estar em sintonia quando percebem a necessidade de tratar os gêneros como híbridos, impuros e atualizados em diferentes níveis ao longo das trocas interacionais.

Nesta perspectiva, para definir uma interação como uma conversa, uma conferência ou um debate, é preciso antes definir o "esquema participativo" (as posiçôes e os papéis) e o implícito social relacionado ao tipo dominante do enquadre interativo (VION, 1996) ${ }^{25}$.

Vion utiliza o termo em francês places que aqui traduziremos como "posiçóes” (roles) (SARANGI, 2010) ${ }^{26}$ para referir-se aos movimentos (verbais e não verbais) dos sujeitos em interação. Segundo o autor, é necessário levar em conta cinco posiçôes que interagem entre si: a posição institucional, dominante, e as demais, subordinadas; posição modular, discursiva, subjetiva e enunciativa, que operam na relação. A posição institucional refere-se ao en-

23 VION, R. L'analyse des interactions verbales. In : La construction interactive des discours de la classe de langue. Les carnets du CEDISCOR, nr. 4, p. 19-32. Paris : Presses de la Sorbonne Nouvelle, 1996.

24 SARANGI, S. "Reconfiguring self/identity/status/role: The case of professional role performance in healthcare encounters". Journal of Applied Linguistics and Professional Practice 7 , 1: 75-95, England, 2010.

25 VION, R. L'analyse des interactions verbales. In : La construction interactive des discours de la classe de langue. Les carnets du CEDISCOR, nr. 4, p. 19-32. Paris : Presses de la Sorbonne Nouvelle, 1996.

26 SARANGI, S. "Reconfiguring self/identity/status/role: The case of professional role performance in healthcare encounters". Journal of Applied Linguistics and Professional Practice 7, 1: 75-95, England, 2010. 
quadre em si, sendo que os sujeitos dispóem de uma tipologia implícita que lhes permite reconhecer o enquadre em que se encontram:

É associando este encontro a um ou mais tipos de interação já experimentados que se pode fazer sentido e dar sentido às atividades e aos enunciados trocados. Esta atitude parece ser necessária a fim de não limitar o enquadre da interação a copresença de duas ou mais pessoas, reduzindo a relaçáo social à descrição positiva de sua aparência (um eu-você-aqui-agora) ou de sua autonomia ${ }^{27}$ (VION, 1996, p. 20-21[tradução $\operatorname{minha})^{28}$.

A posição institucional diz respeito a cenários relativamente precisos e é marcada por restriçóes e regras comportamentais, mas que não restringem os sujeitos a uma única forma de agir e $\operatorname{pensar}^{29}$ (c.f.: GUMPERZ, 2002, p. 152$)^{30}$.

Entre as posições que operam na relação, a posição modular consiste no fato de um dos participantes tomar a iniciativa de abrir um módulo não constitutivo daquela relação ou de se adotar um 'desvio negativo' que aparece como alternativa diante da impossibilidade de se permanecer no módulo

27 C'est en associant cette rencontre à un ou plusieurs types d'interaction déjà expérimenté(s) qu'ils peuvent lui donner un sens et donner ainsi du sens à leurs activités et aux énoncés échangés. Cette attitude paraît nécessaire afin de ne pas limiter le cadre de l'interaction à la seule relation de co-présence de deux ou plusieurs sujets, réduisant la relation sociale à la description positive de son apparence (un moi-toi-ici-maintenant) ou de son autonomie (VION, R. L'analyse des interactions verbales. In : La construction interactive des discours de la classe de langue. Les carnets du CEDISCOR, nr. 4, p. 19-32. Paris : Presses de la Sorbonne Nouvelle, 1996).

28 VION, R. L'analyse des interactions verbales. In : La construction interactive des discours de la classe de langue. Les carnets du CEDISCOR, nr. 4, p. 19-32. Paris : Presses de la Sorbonne Nouvelle, 1996.

29 "O tipo de atividade não determina o significado, mas simplesmente restringe as interpretações, canalizando as inferências de forma a ressaltar ou tornar relevantes certos aspectos do conhecimento prévio e diminuir a importância de outros" (GUMPERZ, J. J. "Convençôes de Contextualização” In: RIBEIRO, B. T.; GARCEZ, P. M. Sociolinguística Interacional. São Paulo: Edições Loyola, 2002, p. 149-182).

30 GUMPERZ, J. J. “Convençôes de Contextualização” In: RIBEIRO, B. T.; GARCEZ, P. M. Sociolinguistica Interacional. São Paulo: Ediçôes Loyola, 2002, p. 149-182. 
vigente. Segundo Vion, o módulo secundário tende a ser menos marcado, caracterizado geralmente pelo enquadre "conversação". O autor dá como exemplo de módulo secundário o caso do paciente (ou o médico) que, durante uma consulta, abandona o script "consulta médica" (marcado pelo relato e as queixas do paciente, a auscultação, a prescrição por parte do médico etc.), para abrir um novo enquadre, no qual assume uma posição que não é implicada pelo enquadre em que estão envolvidos, uma conversa sobre um filme ou uma partida de futebol, por exemplo.

A posição discursiva refere-se à natureza das tarefas executadas pelos sujeitos, seja numa relação institucional ou modular. Ao se comunicarem, os sujeitos são conduzidos a cumprirem algumas tarefas discursivas particulares, "como fazer uma narrativa, uma argumentação, uma explicação, uma descrição [...] que implicam uma distribuição dos papéis discursivos" (VION, 1996, p. 28) ${ }^{31}$. Assim, o fato de se introduzir uma narrativa (tipo de discurso) em uma conversa (tipo de enquadre, enquadre este que pode possuir, no caso de uma dada interação, tanto caráter institucional quanto modular), por exemplo, implica que os participantes, em uma relação simétrica (conversa), vão assumir papéis que são complementares em relação ao tipo de discurso (narrador/narratário).

A posição subjetiva opera de modo semelhante aos trabalhos de face sugeridos por Brown \& Levinson (1987) ${ }^{32}$. Para Vion (1996) ${ }^{33}$, "é neste nível que os sujeitos 'se esforçam' para lisonjear, impressionar e seduzir seus parceiros" e é onde se procura construir imagens que o sujeito deseja ver atribuídas a si próprio e ao outro. É, sobretudo nesse nível, que estão em jogo ou em negociação aspectos identitários, os quais podem ser confirmados, reformulados ou recusados.

Em relação à posição enunciativa, o sujeito pode ou não ser responsável pelo que foi dito, o que vai nos interessar especialmente, uma vez que, através

31 VION, R. L'analyse des interactions verbales. In : La construction interactive des discours de la classe de langue. Les carnets du CEDISCOR, nr. 4, p. 19-32. Paris : Presses de la Sorbonne Nouvelle, 1996.

32 BROWN, P. \& STEPHEN, L. Politeness: Some universals in language usage. Cambridge: Cambridge University Press, 1987.

33 VION, R. L'analyse des interactions verbales. In : La construction interactive des discours de la classe de langue. Les carnets du CEDISCOR, nr. 4, p. 19-32. Paris : Presses de la Sorbonne Nouvelle, 1996. 
do humor, da ironia ou do sarcasmo, o sujeito tem a possibilidade de construir inúmeros posicionamentos enunciativos. Em nossos dados de ironias, constatamos que muitas vezes os participantes “jogam” de modo a distanciar-se dos enunciados, dando voz a outros participantes da interação ou mesmo trazendo outras vozes exteriores às trocas em que se encontram, com o intuito de ridicularizar posiçóes ocupadas pelos parceiros (ou por eles mesmos). Como foi proposto por Sperber e Wilson $(1978)^{34}$, a ironia concebida como menção leva em conta a contraposição entre emprego e mençáo feita na filosofia lógica. Quando um enunciado é empregado, refere-se àquilo que ele representa, ao passo que quando a expressão é mencionada, ela refere-se a uma crença sobre o enunciado. Assim, para os autores, a ironia é um fenômeno metalinguístico que mais se assemelha a uma atitude do falante sobre o mundo do que a um objeto no mundo.

Vejamos este segmento:

1 Ana vamos tomar um portinho

2 Diogo POR-TI-NHO $\uparrow$ agora $\uparrow$

3 Ana QUEM é que teve a INFELIZ ideia de-totalmente sem noção de

4 tomar um PORTINHO agora $\uparrow$ agora $\uparrow$

5 Diogo NÃO-não $\downarrow$ pode tomar $\downarrow$ é que-[não

6 Ana [não, que ideia INFELIZ

7 Diogo é que normalmente a gente toma no final

8 Ana não IMAGINA, depois claro

9 Diogo cara, não enche, toma quando vocês quiserem, DURANTE até $\downarrow$

No segmento apresentado acima, a observação das intervençóes dos sujeitos em interação revela a existência de uma dinâmica que consiste em explorar os diferentes modos de posicionamento a que nos referimos: módulo institucional, modular, discursivo, subjetivo e enunciativo. Ao oferecer um vinho do Porto aos convidados que recebe em sua casa (módulo institucional ou relação dominante), Ana opera dentro daquilo que se espera dela, ajudando a definir

34 SPERBER, D. \& WILSON, D. "Les ironies comme mentions” Poétique, n. 36, 399 - 412, Paris, 1978. 
o enquadre "encontro entre amigos em sua casa", colocando-se como anfitriã e os demais participantes da interação como convidados. No entanto, as posiçóes discursivas adotadas pelos outros participantes e por ela própria em seguida (argumentativas e explicativas), e principalmente as posiçóes enunciativas e subjetivas, marcadas por um distanciamento irônico, tendendo à exageração e à provocação, revelam que, dentro dos papéis institucionais de uma conversa entre amigos, se estabelece um jogo em que um dos participantes, pelo menos, procura, como diria Bateson $(2002)^{35}$, simular uma mordida agressiva, mas dando, ao mesmo tempo, sinais de que se trata na verdade de uma brincadeira.

A brincadeira é um enquadre especialmente complexo, de natureza paradoxal e ambígua e tão instável que pode ser rapidamente transformado numa interação séria, uma vez que, para ser compreendida como uma brincadeira, ela precisa mobilizar uma metamensagem que esclareça não se tratar de um combate. Nas palavras de Bateson, "Estas açóes nas quais estamos presentemente engajados não denotam o que aquelas açóes que elas representam denotariam" (BATESON, 2002, p.89) ${ }^{36}$.

Emrelação ao enquadre da brincadeira, Ribeiro e Hoyle (2002) ${ }^{37}$ afirmam que o enquadre é essencial para qualquer atividade, mas é particularmente saliente durante a brincadeira. Para as autoras,

A criação de um enquadre de provocação é o exemplo essencial de um enquadre que precisa ser reconhecido e ratificado por todos os participantes. Porque se a intenção de se fazer uma provocação é interpretada seriamente, ela não será bem sucedida e resultará em um conflito na comunicação ${ }^{38}$ (RIBEIRO \& HOYLE, 2002, p. 44 [tradução minha]).

35 BATESON, G. Uma teoria sobre brincadeira e fantasia In: RIBEIRO, B. T. \& GARCEZ, P. M. (orgs.) Sociolinguística interacional, São Paulo, Loyola, 2002. p. 85-105.

36 BATESON, G. Uma teoria sobre brincadeira e fantasia In: RIBEIRO, B. T. \& GARCEZ, P. M. (orgs.) Sociolinguística interacional, São Paulo, Loyola, 2002. p. 85-105.

37 RiBEIRO, B. T. \& HOYLE, S. M. "Frame analysis". Palavra. n. 8: 36-53, Rio de janeiro, 2002.

38 The creation of a teasing frame is a prime example of one which must be recognized and ratified by all participants, for if an intended tease is interpreted seriously, it will not succeed and miscommunication will result (RIBEIRO, B. T. \& HOYLE, S. M. "Frame analysis". Palavra. n. 8: 36-53, Rio de janeiro, 2002). 
Ao tratarem do enquadre de brincadeira, as autoras postulam que, enquanto imersas em brincadeiras, as crianças afiam seu uso de enquadres a partir da criação de situaçóes imaginárias, alternando entre suas identidades reais e as identidades imaginadas (RIBEIRO \& HOYLE, 2002, p. 44) ${ }^{39}$.

Há em Sociolinguística Interacional outros autores que procuram entender os enquadres interacionais sem necessariamente optar pela tipologia oferecida por Vion $(1995,1996)$. Estes autores consideram a necessidade de se pensar num enquadre interacional conforme definido por Bateson, como um conceito psicológico, e não físico, que canaliza o entendimento da interação a partir de metamensagens compartilhadas entre participantes. No entanto, nem sempre há a preocupação em tratar dos diferentes níveis de abstração elaborados por Vion, tampouco a necessidade de perceber estes níveis (ou módulos) de forma simultânea e formadora de um todo heterogêneo.

Tannen e Wallat $(2002)^{40}$, por exemplo, analisam uma interação pediátrica, considerando as mudanças de enquadre mobilizadas por uma médica, com seus diferentes interlocutores. A interação analisada é o exame de uma criança conduzido por uma médica, na presença da mãe da paciente e de uma câmera de vídeo, que grava a interação para os residentes do hospital. Para as autoras, há mudança de enquadre sempre que a médica precisa passar de um registro para outro. Isto é, ao se referir à criança a médica usa o maternalês, caracterizado por mudanças exageradas na altura da voz ou pela prosódia marcada; ao se dirigir aos residentes, ela se vale do registro de relato, explicando tecnicamente o que está fazendo ao longo do exame; e com a mãe, a médica aproxima-se do registro convencional da conversa. Segundo as autoras, cada um destes registros contribui para a definição de um enquadre diferente.

Tannen e Wallat (2002) afirmam que as discrepâncias entre os esquemas de conhecimento dos participantes, aos quais a médica dirige a palavra, podem dar origem a mudanças de enquadre, "exercendo sobre ela uma pressão considerável” (TANNEN \& WALLAT, 2002, p. 185) ${ }^{41}$.

39 RiBeirO, B. T. \& HOYLE, S. M. "Frame analysis". Palavra. n. 8: 36-53, Rio de janeiro, 2002.

40 TANNEN, D.; WALLAT, C. "Enquadres interativos e esquemas de conhecimento em interação exemplos de um exame/consulta médica” In: RIBEIRO, B. T.; GARCEZ, P. M. Sociolinguística Interacional. São Paulo: Edições Loyola, 2002, p. 183 - 214.

41 TANNEN, D.; WALLAT, C. Enquadres interativos e esquemas de conhecimento em in- 
Se considerarmos a tipologia proposta por Vion, diríamos que estas mudanças revelam a dinâmica dos diferentes modos de posicionamento adotados num mesmo enquadre dominante que seria a consulta médica. Assim, seria mais fácil explicar os leaky frames definido pelas autoras como as 'escorregadas da médica entre um enquadre e outro', quando ela usa registro de maternalês acidentalmente para dirigir-se à mãe ou aos residentes. Entenderíamos que a carga cognitiva exigida por tal evento, que agrega duas interaçóes conexas (a pediatra + a paciente e a mãe desta, de um lado, e a pediatra + os residentes, de outro) faz com que a médica, vértice de dois esquemas participativos, se posicione 'equivocadamente' em determinados momentos. Sua posição subjetiva (Vion, 1996) ${ }^{42}$ teria sido 'equivocada' em relação àquele momento, naquele contexto. Ela teria evocado uma relação de adulto e criança, ao dirigir-se à mãe, quando na verdade se tratava da relação entre médica e mãe de paciente.

Gordon $(2008)^{43}$, que também estuda a interação entre crianças, adota e estende o conceito de leaky frames proposto por Tannen e Wallat. A autora percebe que na interação entre pais e filhos existem momentos em que as escorregadas entre enquadres, os leaky frames, ocorrem propositalmente, o que define como blending frames. Para Gordon, blending frames é uma estratégia utilizada por pais para imprimir um tom de brincadeira a uma atividade que se espera que a criança realize. É utilizada para que o "trabalho/atividade pareça brincadeira para as crianças ${ }^{44 ”}$ (GORDON, 2008, p. 323 [tradução minha]) ${ }^{45}$

$\mathrm{Na}$ tipologia de Vion, este tom impresso na brincadeira seria representado pelo posicionamento enunciativo. Como exemplo, poderíamos pensar em pais que representam outros papéis como o de um monstro que vai comer a comida da criança se ela não comer. Ao "tornar-se" um monstro o pai, exime-

teração exemplos de um exame/consulta médica. In: RIBEIRO, B. T.; GARCEZ, P. M. Sociolinguística Interacional. São Paulo, Ediçóes Loyola, 2002.

42 VION, R. L'analyse des interactions verbales. In : La construction interactive des discours de la classe de langue. Les carnets du CEDISCOR, nr. 4, p. 19-32. Paris : Presses de la Sorbonne Nouvelle, 1996.

43 GORDON, C. "A(p)parent play: blending frames and reframing in family talk" In: Language in Society 37, 319-349, 2008.

44 "(...) parents use it to make work seem like play to children" GORDON, C. "A(p)parent play: blending frames and reframing in family talk" In: Language in Society 37, 319-349, 2008.

45 GORDON, C. "A(p)parent play: blending frames and reframing in family talk” Language in Society 37: 319-349, 2008. 
-se da culpa de comer a comida da criança e ainda transfere a responsabilidade a um novo enunciador que é alimentado pelo imaginário da criança.

Assim, vemos a importância de caracterizarmos as atividades de fala de modo mais amplo do que simplesmente através da posição institucional e a definição do enquadre. Percebemos que é necessário considerar a atualização destas posiçóes ao longo das trocas interacionais, sem deixar de compreendê-las de forma dialógica e histórica.

\title{
HOW TO DEAL WITH IDENTITIES IN LINGUISTIC RESEARCH
}

\begin{abstract}
This paper investigates the concept of identity through the explanation of a typology developed by Vion (1995, 1996). It intends to demonstrate that, in collaboration with other concepts of Interactional Sociolinguistics such as frames (BATESON, 2002) and genres (KERBRAT-ORECCHIONI \& TRAVERSO, 2004), this typology seems to be productive to understand close relationships in their complexity and heterogeneity.

KEYWORDS: Identities; types of discourse; close relationships
\end{abstract}

Recebido em: 30/06/2012 Aprovado em: 01/02/2013 